\title{
Nano-Structured Defects in an Oxide Superconductor Induced by Au and Fe Ion Irradiation
}

\author{
Yukichi SASAKI, D. X. HUANG, Tsukasa HIRAYAMA and Yuichi IKUHARA* \\ Japan Fine Ceramics Center, 2-4-1, Mutsuno, Atsuta-ku, Nagoya-shi 456-8785 \\ *Institute of Engineering Innovation, The University of Tokyo, 2-11-16, Yayoi, Bunkyo-ku, Tokyo 113-8656 \\ 金及び鉄イオン照射によって酸化物超電導体内に形成されたナノ構造欠 \\ 佐々木優吉·黄 達祥·平山 司·幾原雄一* \\ (財)ファインセラミックスセンター，456-8587 名古屋市熱田区六野 2-4-1 \\ *東京大学工学部総合研究機構, 113-8656 東京都文京区弥生 2-11-16
}

\begin{abstract}
Long columnar nano-defects were formed in $\mathrm{a}_{2} \mathrm{Sr}_{2} \mathrm{CaCu}_{2} \mathrm{O}_{x}$ (Bi2212) single crystal irradiated by $230 \mathrm{MeV} \mathrm{Au}$ and $180 \mathrm{MeV}$ Fe ions. As expected, the width of the columnar defects induced by the heavy Au ion irradiation gradually decreased with the loss of ion energy in the target along the ion trace. However, in the case of irradiation by the lighter $\mathrm{Fe}$ ions, the width of the columnar defects remained almost constant along the ion trace. The conditions required for producing the same type of damage morphology in the same target are very different for the two types of ions, strongly depending on the ion momentum, and hence mass. The relationships between the ion energy and the columnar defect size produced by the two types of irradiation are discussed quantitatively. The relationships are found to be useful for predicting the diameters and distribution of the columnar defects formed by ion irradiation.

[Received September 15, 2004; Accepted November 26, 2004]
\end{abstract}

Key-words : Ion irradiation, Columnar defect, $\mathrm{Bi}_{2} \mathrm{Sr}_{2} \mathrm{CaCu}_{2} \mathrm{O}_{x}$, Transmission electron microscopy

\section{Introduction}

In superconducting oxides, the magnetic vortices are easily moved under Lorentz forces, resulting in the dissipation of energy and limiting of the critical current density $\left(J_{c}\right)$. Irradiations with protons, neutrons and various heavier ions have been carried out to artificially introduce crystallographic defects that provide effective pinning sites for the vortices. ${ }^{1)}$ Large increases in $J_{c}$, especially at high temperatures and fields, have been observed in single crystals, thin films, and bulk ceramics irradiated with high-energy heavy ions that produced amorphous columnar defects. ${ }^{2)-11)}$ The size and density of the induced columnar defects have been found to strongly influence the flux-pinning efficiency. By controlling the ion dose in the irradiation experiments, the defect density can be easily controlled. To optimize the defect size, we have to control the projectile species and energy. However, to our knowledge, the relationships between the irradiation-induced defect morphology and the irradiation conditions have so far not been adequately elucidated.

For high-energy ion irradiation, the dominant mode of energy transfer from fast ions to the target lattice is through electronic ionization and excitation; fast ion energy losses through nuclear collisions with target atoms are at least two orders of magnitude smaller. Hence, the defect formation mechanism is thought to rely largely on the magnitude of the electronic energy loss $\left(S_{\mathrm{e}}\right)$. In this paper, we relate ion energy and $S_{\mathrm{e}}$ to the observed defect structures for Bi2212 single crystals irradiated by different ions. Cross-sectional transmission electron microscopy (TEM) has been employed to characterize the evolution of the structural damage along the ion trace resulting from irradiation with $230 \mathrm{MeV} \mathrm{Au}$ and 180 $\mathrm{MeV} \mathrm{Fe}$ ions. The different damage behaviors caused by $\mathrm{Au}$ and $\mathrm{Fe}$ ion irradiation have been revealed and the relationships between the columnar defect width and the projectile energy determined.

\section{Experimental methods}

Bi2212 single crystals were prepared by the floating-zone melting method. ${ }^{12)}$ Before ion irradiation the crystals were cleaved into crystal sheets, then cut to a size of $1 \times 2 \mathrm{~mm}^{2}$ parallel to the $a$ and $b$ axes. The sample thickness was controlled to be about $25 \mu \mathrm{m}$, which was thicker than the estimated ion penetration length. $230 \mathrm{MeV} \mathrm{Au}$ and $180 \mathrm{MeV}$ Fe ion beams were used to irradiate the Bi2212 thin sheets at room temperature. The incident high-energy ions were produced by a Tandem accelerator at the Japan Atomic Energy Research Institute. The beam incident direction was along the $\mathrm{c}$ direction of the target crystals (normal to the surface of the thin crystal sheet). The ion doses used were about $9.7 \times 10^{10}$ and $3.3 \times 10^{11}$ ions $/ \mathrm{cm}^{2}$ for $\mathrm{Au}$ and $\mathrm{Fe}$ ions, respectively.

Cross-sectional samples of the irradiated $\mathrm{Bi} 2212$ thin sheets were prepared by the following method. An irradiated thin sheet was first sandwiched between two silicon pellets and the bundle pasted together using Gatan G1 glue. Normal to the sample surface $(a-b$ plane), the pasted sample was cut into slices along the $a$ - or $b$-axis. The slices were then mechanically polished to about $50 \mu \mathrm{m}$ thickness, dimpled to about $10 \mu \mathrm{m}$, and finally ion-milled on a liquid-nitrogen cold stage. To successfully observe the change in defect morphology along the ion trace, a wide, elongated area of about $20 \mu \mathrm{m}$ in length along the ion incident direction was required. A series of lowand high-resolution images along the ion trace for both samples were taken using a Topcon EM-002B high-resolution TEM operating at $200 \mathrm{keV}$ with a point-to-point resolution of $0.18 \mathrm{~nm}$. The changes in ion energy, ion velocity, and electronic stopping power, $S_{\mathrm{e}}$, for $\mathrm{Au}$ and $\mathrm{Fe}$ ions along the ion traces were estimated using a high-energy-extended EDEP-1 code. ${ }^{13)}$

\section{Irradiation-induced defect structures}

Figure 1 shows a series of low-magnification and high-resolution images taken along the ion penetration path in a 230 


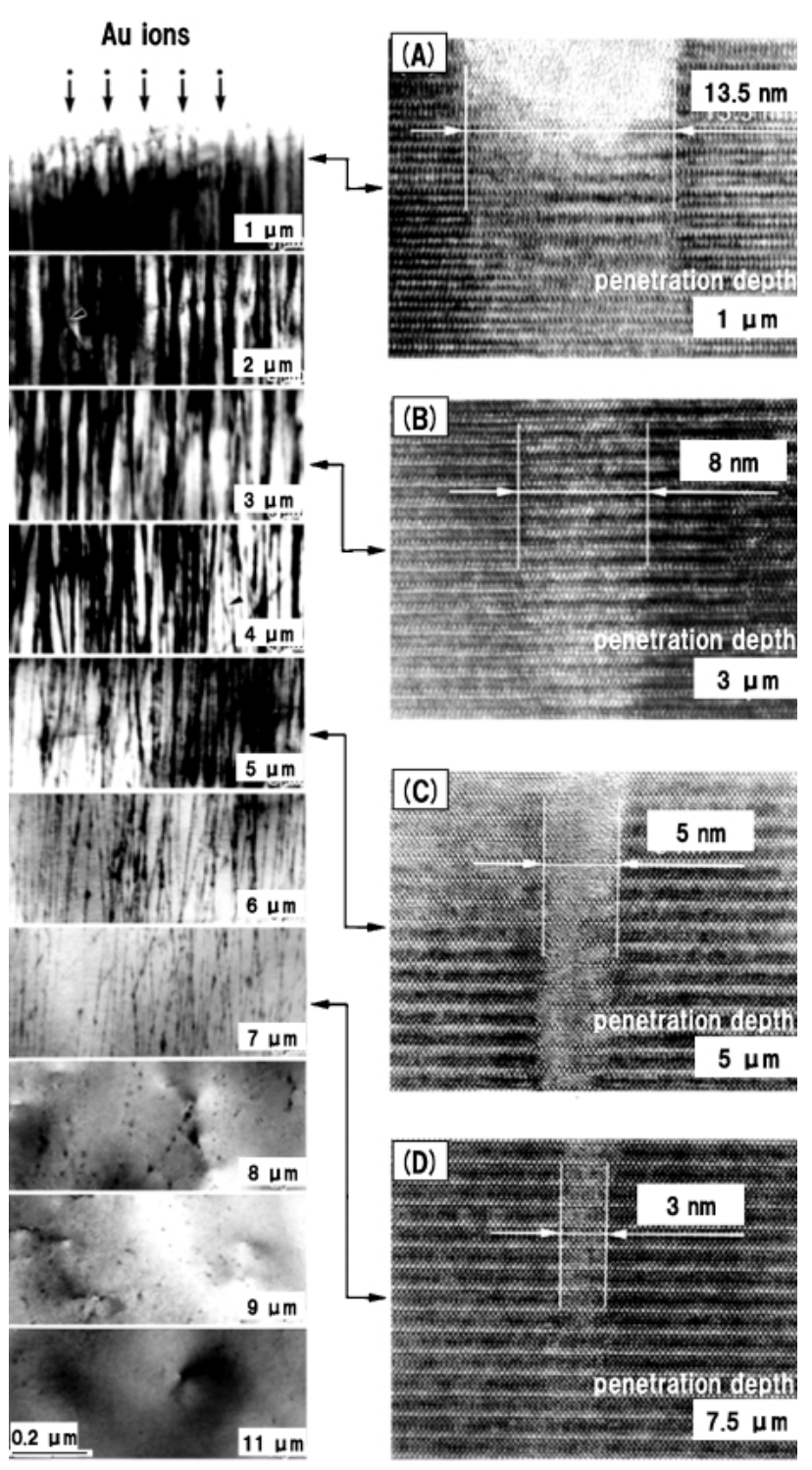

Fig. 1. Left side is a series of bright field images taken at equidistant points along an Au ion trace. The corresponding depth from the ionbombarded surface is given in the bottom corner of each image. The black triangles indicate the large-angle-deflected columnar defects. The right side contains four high-resolution images taken at four different ion-penetration depths showing the change in the diameter of a columnar defect in detail.

$\mathrm{MeV}$ Au-irradiated $\mathrm{Bi}_{2} \mathrm{Sr}_{2} \mathrm{CaCu}_{2} \mathrm{O}_{\mathrm{x}}$ crystal. From Fig. 1, we can clearly see the change in the irradiation-induced defect morphology as the $\mathrm{Au}$ ions move and exchange their energy gradually with the target crystal. The irradiation-induced defects can be divided into five types, depending on the ion energy. ${ }^{8)}$

(1) Parallel columnar defects. Near the irradiated surface layer, the defects generated by the incident ions with very high energy were amorphous columns oriented almost parallel to the ion incident direction. When they penetrated into the target, the ions slowed down through interaction with the target electrons and/or atoms. The width of the amorphous column each ion produced decreased gradually.

(2) Large-angle-deflected columnar defects. Starting from a depth of $2 \mu \mathrm{m}$, we found a few columnar defects were deflected from the ion incident direction by angles larger than $30^{\circ}$. As the ions penetrated deeper, the density of the largeangle-deflected columnar defects increased gradually. In this ion energy regime, the produced defects are usually a mixture of parallel and large-angle-deflected defects.

(3) Combined cascade and columnar defects. When the ions penetrated to a depth of about $5 \mu \mathrm{m}$ and their energy had been reduced to some critical value (e.g., about $100 \mathrm{MeV}$ for $\mathrm{Au}$ ), we found a region containing both columnar defects and cascade defects. The cascade defects occurred at regular intervals along the axes of columnar defects, as can be seen in Fig. 1, which shows an image taken at a depth of $7 \mu \mathrm{m}$.

(4) Ordered cascade defects. As ion energy decreased further into the target crystal, the continuous columnar defects disappeared and only cascade defects were able to be observed. It was found that the cascade defects, generated by the ions in this energy regime, were distributed along lines (see the image in Fig. 1 taken at a depth of $84 \mu \mathrm{m}$ ).

(5) Disordered cascade defects. At depths beyond those of the ordered cascade defects, only disordered spherical cascade defects were found. As the ions penetrated deeper, the density of the cascade defects decreased gradually. Finally, when the ions penetrated deeper than $11 \mu \mathrm{m}$, no cascade defects were able to be observed by TEM.

The width of a columnar defect along the ion trace was estimated using the high-resolution TEM images. As an example, in Fig.1 four high-resolution images of taken at points (A), (B), (C) and (D) are shown from which we were able to measure the diameter of the columnar defect at different ionpenetration depths directly. The diameter of the columnar defect was found to decrease gradually from 13.5 to $3 \mathrm{~nm}$ as the ion-penetration depth in the target increased from 1 to 7.5 $\mu \mathrm{m}$.

Similar TEM analyses were performed also for the 180 $\mathrm{MeV}$ Fe-irradiated sample. As shown in Fig. 2, five types of irradiated damage morphologies similar to those found for $\mathrm{Au}$ irradiation were observed. The length of the columnar defect was about $13.5 \mu \mathrm{m}$, about two times longer than those produced by $230 \mathrm{MeV}$ Au irradiation. High-resolution TEM observations revealed that the width of the columnar defect along the ion trace was constant. The high-resolution images (a), (b) and (c) show details of the columnar defect for three different regions with ion-penetration depths of about $0.5,6$, and $13.5 \mu \mathrm{m}$, respectively.

Figure 3 is a schematic showing the changes in the irradiation-induced damage morphologies along the ion traces for both samples. Values for the penetration depths, ion energies and electronic stopping powers for both incident ions are also given in the figure showing the conditions necessary to generate various defect morphologies in Bi2212 crystals. Comparison of the defects generated by the two kinds of incident ions shows the sequence of irradiation damage morphologies is similar in both cases. However, the changes in columnar defect widths along the ion traces in the two samples were very different. The heavier Au ions produced short, wide columnar defects, while the columnar defects introduced by the lighter Fe ions were much narrower and longer. The width of the columnar defects increased along the $\mathrm{Au}$ ion trace but remained constant along the $\mathrm{Fe}$ ion trace. The conditions for generating irradiation defects are also very different for the two ions. The lighter Fe ions were able to generate the same type of defect in Bi2212 single crystals at much lower energy and stopping power than the heavier Au ions. For example, to produce columnar defects the minimum energy and stopping power for $\mathrm{Fe}$ ions are about $22 \mathrm{MeV}$ and $9 \mathrm{keV} / \mathrm{nm}$, respectively; however for $\mathrm{Au}$ ions they are about $50 \mathrm{MeV}$ and 16 

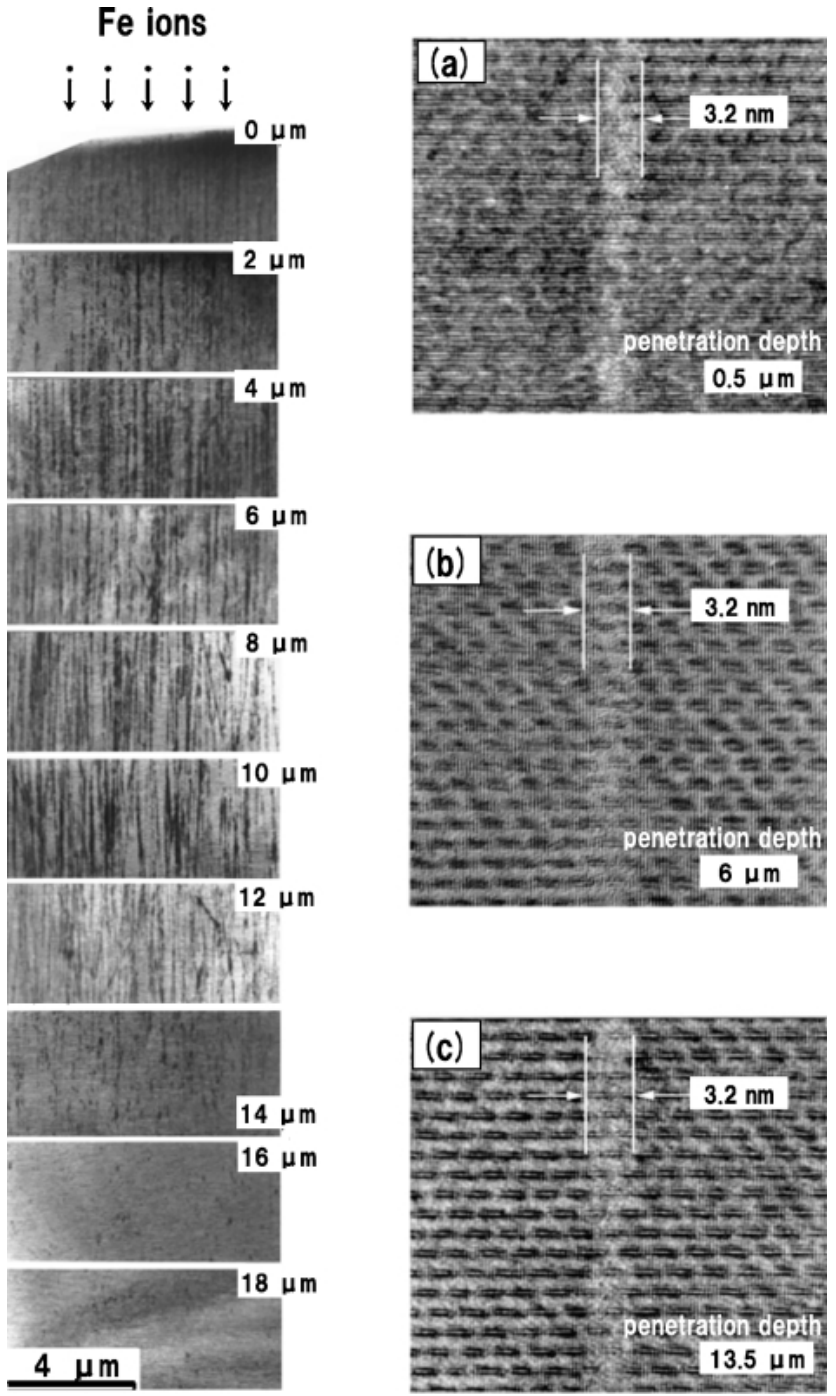

Fig. 2. Left side is a series of bright field images taken at equidistant points along an Fe ion trace. The right side contains three high-resolution images taken at three different ion-penetration depths showing the constant width of a columnar defect along the ion trace.

$\mathrm{keV} / \mathrm{nm}$, respectively. To produce cascade defects detectable by TEM observation, the minimum energy and stopping power for Fe ions are about $0.6 \mathrm{MeV}$ and $0.08 \mathrm{keV} / \mathrm{nm}$, respectively; however for $\mathrm{Au}$ ions they are about $10 \mathrm{MeV}$ and $8 \mathrm{keV} /$ $\mathrm{nm}$, respectively.

\section{Data for predicting columnar defect}

High-energy ion irradiation experiments require specialized, high cost equipment, such as a Tandem accelerator, to generate high-energy projectiles. Only a few laboratories in the world can undertake this kind of experiments. In order to use the irradiation equipment efficiently, calculation of the expected defect morphology before carrying out the experiments is highly desirable. Since the physical properties of the target material usually depend strongly on the defect structures, this kind of estimate can also provide a convenient way of analyzing the mechanisms by which irradiation induces changes in the physical properties of the target material. So far, to our knowledge, no comprehensive data sets have been established for this purpose. In this study, using our experiment results, we construct a small database for estimating the columnar defect size prior to irradiation for specific systems, namely $\mathrm{Au}-\mathrm{Bi} 2212$ and $\mathrm{Fe}-\mathrm{Bi} 2212$.

As described in the methods section, the columnar defect diameters along the ion trace were systematically measured using high-resolution TEM. Figure 4(a) shows the distribution of the columnar defect diameters with ion-penetration depth produced by $\mathrm{Au}$ and $\mathrm{Fe}$ ions. Using the high-energy extended EDEP-1 code, ${ }^{13)}$ we calculated the depth profiles of the residual ion energy and the stopping power in Bi2212 crystals. Next we linked the columnar defect diameter with the ion energy, as shown in Fig. 4(b). Once the initial projectile energy has been selected, the size and distribution of the columnar defects can be easily predicted using this plot for both $\mathrm{Au}$ - and Fe-Bi2212 irradiated systems.

Similarly, a link was also found between the columnar defect diameter and the electronic stopping power, as shown in Fig. 5. The two data for the highest stopping powers in the $\mathrm{Au}-\mathrm{Bi} 2212$ irradiation system (Fig. 5) were taken from $\mathrm{Zhu}$ et al. ${ }^{4)}$ and Wiesner et al.. ${ }^{5)}$ It was found that the columnar defect diameter did not change monotonically with increasing stopping power in the case of Au irradiation. First, the columnar defect diameter increased with increased stopping power. At a certain value of stopping power, the columnar defect diameter reached a maximum. When the stopping power was increased further, the columnar defect diameter decreased. Currently, most researchers estimate the width of columnar defects from the value of stopping power alone. ${ }^{6)}$ Our results indicate that this estimation method is inaccurate and unreliable when the ion energy is very high. For Fe ions, the columnar defect diameter showed no change with change in stopping power.

\section{Concluding remarks}

Based on systematic cross-sectional TEM observations along the ion traces, we have analyzed irradiation damage caused by $230 \mathrm{MeV} \mathrm{Au}$ and $180 \mathrm{MeV} \mathrm{Fe}$ ions in Bi2212 single crystals. The damage morphology was able to be classified into five different types (parallel columnar defects, largeangle-deflected columnar defects, combined cascade and columnar defects, ordered cascade defects and disordered cascade defects) in sequence along the ion traces in both samples. However, the damage behaviors are very different for the two kinds of ions due to the difference in their ion mass. The columnar defects produced by the heavier $\mathrm{Au}$ ions have a larger diameter and shorter length than those produced by the lighter $\mathrm{Fe}$ ions. The width of a columnar defect gradually decreases along an $\mathrm{Au}$ ion trace, but remains constant along an $\mathrm{Fe}$ ion trace. The required ion energies and stopping powers for producing the five different damage morphologies are much lower in the case of $\mathrm{Fe}$ ion irradiation than for $\mathrm{Au}$ ion irradiation. The relationship between the columnar defect diameter and the ion energy revealed by this study can help us to predict accurately the size and distribution of columnar defects before ion irradiation is applied.

Acknowledgements The authors would like to thank Drs. Satoru Okayasu, Takeo Aruga and Kiichi Hojou of the Japan Atomic Energy Institute for their collaboration during the irradiation experiments.

\section{References}

1) Weber, H. W. and Carbtree, G. W., "Studies of High Temperature Superconductors," Vol. 9, Nova Science Publishers, New York (1992) pp. 37-59.

2) Hensel, B., Roas, B., Henke, S., Hopfengärtner, R., Lippert, M., Ströbel, J. P., Vildić, M. and Saemann-Ischenko, G., Phys. 


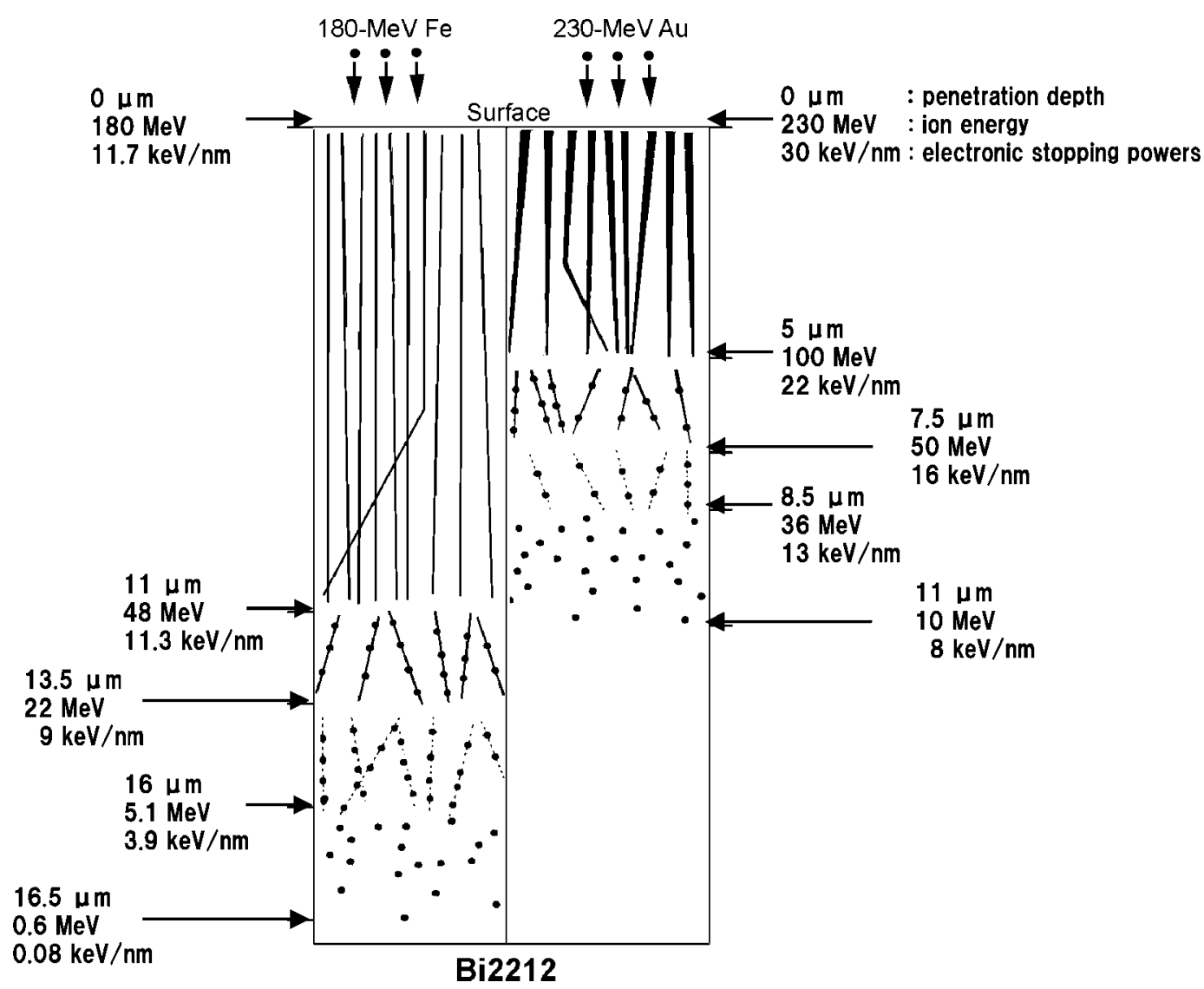

Fig. 3. Schematic showing the change in damage morphology along an ion trace in both Au- and Fe-irradiated Bi2212 crystals. The penetration depths, ion energies and values of the electronic stopping power are also shown for both Au and Fe ions, from which the conditions necessary to produce various damage morphologies in the target material can be determined for both types of irradiation. (Csa.: cascade defect region)
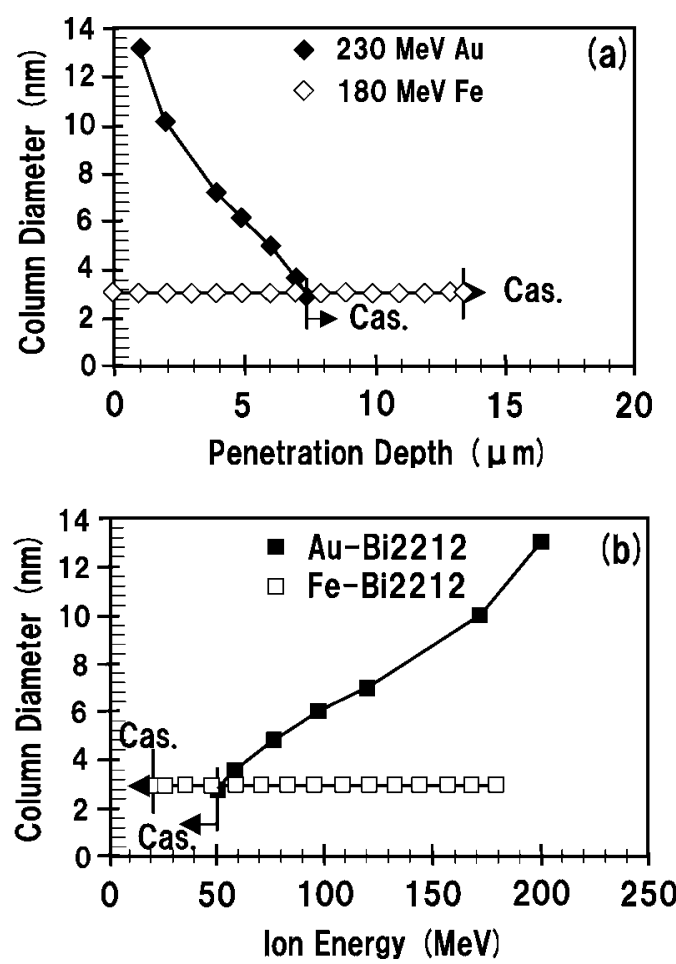

Fig. 4. (a) Change in diameter of columnar defects with penetration depth for both $230 \mathrm{MeV}$ Au and $180 \mathrm{MeV}$ Fe ions in Bi2212 crystals. (b) Change in diameter of columnar defects with ion energy. (Csa.: cascade defect region)

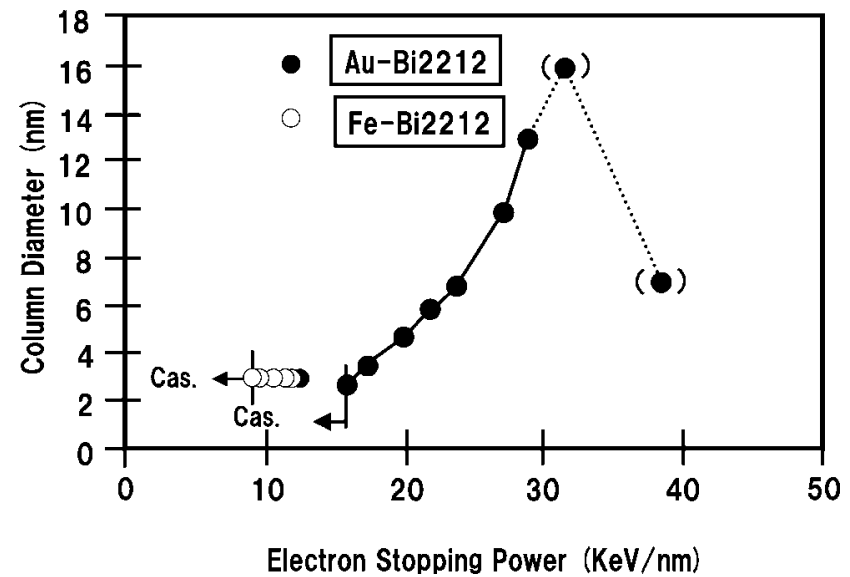

Fig. 5. Change in diameter of columnar defects as a function of stopping power for $\mathrm{Au}$ and $\mathrm{Fe}$ ions in Bi2212 crystals.

Rev. B, Vol. 42, pp. 4135-4142 (1990).

3) Kumakura, H., Kitaguchi, H., Togano, K., Maeda, H., Shimoyama, J., Okayasu, S. and Kazumata, Y., J. Appl. Phys., Vol. 74, pp. 451-457 (1993).

4) Zhu, Y., Cai, Z. X., Budhani, R. C., Suenaga, M. and Welch, D. O., Phys. Rev. B, Vol. 48, pp. 6436-6450 (1993).

5) Wiesner, J., Traholt, C., Wen, J. G., Zandbergen, H. W., Writh, G. and Fuess, H., Physica C, Vol. 268, pp. 161-172 (1996). 
6) Wheeler, R., Kirk, M. A., Marwick, A. D., Civale, L. and Holtzberg, F. H., Appl. Phys. Lett., Vol. 63, pp. 1573-1576 (1993).

7) Krusin-Elbaum, L., Thompsob, J. R., Wheeler, R., Marwick, A. D., Li, C., Patel, S., Shaw, D. T., Lisowski, P. and Ullmann, J., Appl. Phys. Lett., Vol. 62, pp. 3331-3334 (1994).

8) Huang, D. X., Sasaki, Y., Okayasu, S., Aruga, T., Hojou, K. and Ikuhara, Y., Phys. Rev. B, Vol. 57, pp. 13907-13914 (1998).

9) Huang, D. X., Sasaki, Y. and Ikuhara, Y., Phys. Rev. B, Vol.
59, pp. 3862-3869 (1999).

10) Huang, D. X., Sasaki, Y., Hirabayashi, I. and Ikuhara, Y., Phys. Rev. B, Vol. 61, pp. 15442-15448 (2000).

11) Kano, F., Terasawa, M., Mitamura, T., Kambara, T., Sasaki, Y. and Ikuhara, Y., Mat. Res. Soc. Symp. Proc., Vol. 792, pp. 459-464 (2004).

12) Gu, G. D., Takamuku, K., Koshizuka, N. and Tanaka, S., J. Cryst. Growth, Vol. 130, pp. 325-329 (1993).

13) Aruga, T., Nakata, K. and Takamura, S., Nucl. Instr. and Meth. in Phys. Res. B, Vol. 33, pp. 748-751 (1988). 